\title{
ANALISIS POLA DISTRIBUSI BATUBARA UNTUK IKM PENGGUNA GASMIN BATUBARA DI DAERAH ISTIMEWA YOGYAKARTA
}

\author{
Analysis of Coal Distribution for Coal Gasmin Users in the Special \\ Region of Yogyakarta
}

\author{
TRISWAN SUSENO* dan MEITHA SUCIYANTI** \\ Puslitbang Teknologi Mineral dan Batubara \\ Jalan Jend. Sudirman 623 Bandung 40211 \\ Telp. (022) 6030483; Fax. (022) 6003373 \\ e-mail: triswan.suseno@esdm.go.id \\ * Kontributor Utama $\quad * *$ Kontributor Anggota
}

\begin{abstract}
ABSTRAK
Daerah Istimewa Yogyakarta adalah salah satu wilayah yang sarat berbagai jenis industri kecil dan menengah, terutama industri yang memanfaatkan panas (api) untuk memasak menggunakan bahan bakar kayu, oli bekas, solar atau lainnya. Gasmin batubara adalah salah satu produk Puslitbang tekMIRA yang dapat menjadi pilihan industri kecil dan menengah (IKM) dalam memasak atau memanaskan suatu produk. Untuk mengetahui potensi pasar gasmin pada IKM dapat diketahui melalui diskusi kelompok terfokus, wawancara dan kunjungan langsung ke lokasi perusahaan. Hasil pengukuran pasar gasmin di Daerah Istimewa Yogyakarta menunjukkan bahwa ada 97 perusahaan yang berpotensi menggunakan gasmin, yaitu 29 perusahaan di Sleman, 17 perusahaan di Bantul, 6 perusahan di Gunung Kidul, 9 perusahaan di Kulon Progo dan 36 perusahan di Kota Yogya. Batubara yang dibutuhkan untuk memenuhi permintaan 97 perusahaan tersebut sebanyak 437 ton. Metode yang digunakan untuk mendistribusikan 437 ton ke masing-masing perusahaan di lima lokasi tersebut adalah metode pemrograman linier. Tujuan yang ingin dicapai adalah optimalisasi pengiriman batubara ke masing-masing lokasi dengan biaya yang paling minimum. Hasil perhitungan yang paling optimal menunjukkan hal-hal sebagai berikut: permintaan batubara dari Yogya dapat dipasok oleh PT. GAC yang ada di Cirebon sebesar 98 ton, dan PT. MBS (Demak) sebesar 64 ton. Permintaan dari Bantul bisa dipasok dari Semarang dan Kendal, masing-masing 27 dan 53 ton. Kebutuhan batubara di Gunung Kidul cukup dipenuhi oleh pemasok dari Semarang sebanyak 23 ton, sedangkan permintaan batubara dari Kulon Progo dapat dipasok dari Demak dan Semarang, masing-masing sebanyak 29 dan 21 ton. Total biaya pengiriman yang harus dikeluarkan dari lokasi pemasok ke lima lokasi pemesan yaitu Rp. 39.920.000. Metode ini mampu menunjukkan rekomendasi jumlah pengiriman batubara yang sesuai dengan kebutuhan pemesan melalui jalur terpilih dengan biaya paling minimal.
\end{abstract}

Kata kunci: gasmin, batubara, depo, pemasok, IKM.

\begin{abstract}
The Special Region of Yogyakarta or DIY is one of the areas that has various types of small and medium industries, especially industries that use heat (fire) to cook using wood fuel, used oil, diesel or other. Coal gasmin is one of the products of the Research and Development Centre For Mineral and Coal Technology which can be an option for small and medium industries to cook or heat the products. To find out about the potential market of gasmin's in small and medium industries, it can be figured out through a focus group discussion, interview and direct visit to company locations. The measurement results of the gasmin market in DIY show that there are 97 companies that have the potential to use gasmin, namely 29 companies in Sleman, 17 companies in Bantul, 6 companies in Gunung Kidul, 9 companies in Kulon Progo and 36 companies in Yogya. The coal needed to meet the demands
\end{abstract}


of the 97 companies is 437 tonnes. The method used to distribute 437 tonnes to each company in five locations is linear programming method. The objective is to optimize the coal delivery to each location with the minimum cost. The most optimal calculation results show that the coal demand from Yogya can be supplied by PT. GAC in Cirebon (98 tons) and PT. MBS of Demak (64 tons). The demand from Bantul can be supplied from Semarang and Kendal, respectively 27 and 53 tons while the demand of coal in Gunung Kidul is fulfilled by a supplier from Semarang (23 tons). Meanwhile, coal demand of Kulon Progo can be supplied by mining companies from Demak and Semarang, as much as 29 and 21 tons, respectively. The total shipping cost that must be incurred from the supplier's location to the five customer locations is Rp. 39,920,000. This method is able to show recommendations for the number of coal shipments that suit the customer needs via the selected route with the least cost.

Keywords: gasmin, coal, depots, suppliers, small and medium industries.

\section{PENDAHULUAN}

Gasmin (gasifikasi mini) adalah reaktor gasifikasi untuk mengubah batubara menjadi gas. Gasmin sangat cocok digunakan oleh industri kecil dan menengah (IKM) yang biasa menggunakan tungku, oven atau boiler untuk memanaskan atau memasak. Jenis IKM yang bisa memanfaatkan gasmin ini antara lain industri tahu, tempe, peleburan alumunium, pengeringan gabah, pengeringan kayu, kerupuk, kecap dan lain-lain.

Salah satu daerah sasaran pasar gasmin adalah Daerah Istimewa Yogyakarta (DIY), mengingat daerah ini mempunyai beragam IKM dan bahan bakar yang digunakan untuk memasaknya, sehingga daerah ini layak dijadikan sebagai sasaran pasar gasmin.

Untuk mengetahui IKM yang berminat terhadap gasmin, dilakukan sosialisasi dan promosi produk terhadap para IKM melalui forum diskusi terfokus terhadap beberapa jenis IKM. Para IKM tersebut berasal dari berbagai daerah di DIY, yaitu Sleman, Kulonprogo, Bantul, Yogya dan Gunung Kidul. Dari forum ini, selain akan diketahui jumlah dan jenis IKM yang berminat untuk memiliki gasmin juga akan diketahui jumlah kebutuhan batubara sesuai jumlah gasmin di setiap daerah. Permasalahan yang muncul adalah bagaimana cara memenuhi kebutuhan batubara untuk para IKM di berbagai daerah tersebut yang menggunakan gasmin mengingat DIY bukanlah daerah penghasil batubara. Oleh karena itu, harus diupayakan untuk mencari perusahaan-perusahaan yang menjadi penghasil atau penjual batubara sebagai pemasok kebutuhan batubara untuk IKM pengguna gasmin di DIY. Hal ini ditempuh untuk menjaga kelangsungan proses gasmin dalam mendukung kegiatan produksi IKM.
Berdasarkan hasil survei, terdapat beberapa lokasi perusahaan yang dapat dipertimbangkan menjadi pemasok kebutuhan batubara untuk IKM di DIY. Lokasi pemasok yang secara geografis dekat dengan DIY adalah Cirebon (Jawa Barat), Demak, Semarang, Kendal dan Karanganyar (Jawa Tengah).

Transportasi sangat erat kaitannya dengan pendistribusian atau pengangkutan batubara dari beberapa pemasok terpilih ke beberapa tujuan pengguna batubara dengan biaya paling kecil atau minimal. Selain itu, kuantitas, kualitas, ukuran, harga dan jarak lokasi pemasok menjadi pertimbangan dalam mengangkut batubara ke IKM pengguna batubara. Tulisan ini mengkaji pola distribusi batubara bagi IKM pengguna gasmin, agar keberlanjutan produksi dapat terjamin dengan ketersediaan batubara.

\section{METODE}

\section{Metode Pengumpulan Data}

Pengumpulan data dilakukan melalui kelompok diskusi terfokus yang diikuti oleh seratus sebelas peserta dari berbagai IKM tertentu dan berbagai daerah yang dipilih berdasarkan kriteria yang telah ditetapkan sesuai dengan karakteristik gasmin, yaitu lama memasak minimal 5 jam.

Untuk menghitung jumlah kebutuhan batubara yang digunakan oleh IKM yang potensial menggunakan gasmin, terlebih dahulu harus diketahui kebutuhan gasmin di Daerah Istimewa Yogyakarta. Di samping itu melalui diskusi kelompok terfokus, metode pengumpulan data juga dilakukan dengan wawancara disertai kuesioner, testimoni dan pengenalan produk dengan melakukan kunjungan ke industri yang sudah 
menggunakannya. Hasil yang diperoleh menunjukkan bahwa dari 414 perusahaan (IKM) yang potensial menggunakan gasmin ada 97 perusahaan; 46 perusahaan di antaranya adalah perajin batik, 11 perusahaan di bidang usaha makanan/minuman dan 36 perusahaan peleburan alumunium (Suseno dan Suherman, 2020).

Kebutuhan batubara untuk IKM pengguna gasmin di Sleman sebesar 122 ton, Bantul sebanyak 80 ton, Kulonprogo sebanyak 23 ton, Gunung Kidul sebanyak 50 ton dan Yogya sebanyak 162 ton.

Sebagaimana telah dijelaskan di atas bahwa tujuan pembuatan model pengangkutan ini adalah untuk meminimumkan biaya pengangkutan batubara dari beberapa lokasi pilihan ke lokasi pengguna batubara yaitu IKM pemilik gasmin. Model ini telah digunakan pula oleh Fahmi, Tety dan Rifai (2014). Untuk mengangkut batubara dibutuhkan alat angkut darat dan memerlukan biaya untuk mengangkutnya (Nirwansah dan Widowati, 2007). Transportasi menjadi salah satu faktor penting dalam pengangkutan batubara. Nirwansah dan Widowati (2007) serta Simbolon, Situmorang dan Napitupulu (2014) menyatakan bahwa ciri-ciri khusus persoalan transportasi adalah:

1. Terdapat sejumlah sumber dan sejumlah tujuan tertentu;

2. Kuantitas komoditas atau barang yang didistribusikan dari setiap sumber dan yang diminta oleh setiap tujuan besarnya tertentu;

3. Komoditas yang dikirim atau diangkut dari suatu sumber ke suatu tujuan besarnya sesuai dengan permintaan dan kapasitas sumber;

4. Ongkos pengangkutan komoditas dari suatu sumber ke suatu tujuan besarnya tertentu.

\section{Model Analisis}

Model yang digunakan dalam analisis ini adalah pemrograman linier yaitu suatu teknik perencanaan pengiriman batubara memakai model matematika, dengan tujuan menemukan beberapa kombinasi alternatif pengiriman batubara dari beberapa lokasi penjualan (pemasok) ke beberapa lokasi pembeli (konsumen) sehingga dapat digunakan untuk menyusun strategi dan langkah-langkah kebijakan lanjut pengalokasian batubara guna mencapai tujuan dan sasaran yang diinginkan secara optimal (Josua, 2014). Pemprograman linier adalah metode matematika dalam mengalokasikan sumber daya terbatas untuk mencapai suatu tujuan seperti memaksimalkan keuntungan atau meminimumkan biaya (Zulfaqor, 2017). Tujuan pemodelan pengangkutan batubara ini adalah untuk mendapatkan jumlah batubara dari setiap lokasi pemasok secara tepat ke IKM pengguna gasmin (konsumen batubara) di Daerah Istimewa Yogyakarta dengan biaya paling minimal.

Variabel yang diperlukan dalam menentukan alternatif proses transportasi adalah lokasi pengiriman (pemasok) dan lokasi tujuan (permintaan) yang di dalam proses pengirimannya mempertimbangkan jarak, harga, jumlah pemasokan dan permintaan. Misalkan terdapat $\mathrm{m}$ perusahaan pemasok batubara, yang masing-masing tersedia sejumlah ai $(i=1,2, \ldots$, n) unit batubara. Terdapat $n$ tempat tujuan, yang masing-masing membutuhkan $b j(j=1,2$, ..., n) unit batubara. Bilangan ai dan bj adalah bilangan bulat positif. Biaya transportasi dari satu pemasok ke-i ke tempat tujuan ke-j diketahui untuk tiap-tiap i dan $\mathrm{j}$, yaitu sebesar Cij (Bronson, 1991). Dengan menganggap bahwa total penawaran (supply) dan permintaan (demand) sama, maka:

$\sum_{i=1}^{m} a_{i}=\sum_{j=1}^{n} b_{j}$

Apabila Xij adalah jumlah unit batubara yang akan dikirim dari sumber i ke tempat tujuan j, maka tujuan penyusunan ini adalah untuk meminimumkan total biaya pengiriman batubara (Supranto, 1983; Nasendi dan Affendi, 1985). Model matematik bagi persoalan tersebut dapat dilihat di bawah ini.

Meminimumkan : $\mathrm{Z}=\sum_{\mathrm{i}=1}^{\mathrm{m}} \sum_{\mathrm{j}=1}^{\mathrm{n}} \mathrm{c}_{\mathrm{ij}} \mathrm{x}_{\mathrm{ij}}$

Dengan batasan

Penyediaan : $\sum_{\mathrm{j}=1}^{\mathrm{n}} \mathrm{X}_{\mathrm{ij}}=\mathrm{a}_{\mathrm{i}} ;(\mathrm{i}=1, \ldots, \mathrm{m})$

Permintaan : $\sum_{i=1}^{m} X_{i j}=b_{i} ;(j=1, \ldots, n)$

Ketidaknegatifan : $X_{i j}>0$

dalam hal ini:

$X_{i j}=$ jumlah batubara yang diangkut dari pemasok i ke titik tujuan j,

$\mathrm{ai}_{\mathrm{i}}=$ jumlah yang disediakan untuk diangkut (jumlah pasokan) di titik asal i,

$b_{j}=$ jumlah yang diminta untuk didatangkan (jumlah permintaan) di titik tujuan $\mathrm{j}$, 
$\mathrm{C}_{\mathrm{ij}}=$ ongkos angkut per unit produk $\mathrm{X}_{\mathrm{ij}}$ yang bersangkutan dari lokasi sumber daya i ke lokasi tujuan j,

$h_{i j}=$ harga batubara di lokasi pemasok,

$\mathrm{m}=$ jumlah pusat (titik) pemasok,

$\mathrm{n}=$ jumlah pusat (titik) permintaan

Tujuan utama transportasi batubara ini adalah menentukan jumlah batubara yang harus dikirim dari masing-masing pemasok ke daerah tujuan dengan tujuan meminimumkan biaya pengiriman (Karo, 2016).

\section{Pembatasan Masalah}

Menurut Wijayanti (2011), pembatasan masalah menjadi hal yang penting untuk mencapai tujuan yang diinginkan. Pembatasan masalah dalam kajian ini meliput:

1. Biaya transportasi untuk produk, dari lokasi pemasok sampai ke lokasi penerima;

2. Jumlah kebutuhan dari tiap pemasok dan permintaan dari tiap pemesan telah ditentukan sesuai dengan kebutuhan;

3. Penelitian dilakukan di wilayah Jawa Barat,

DI Yogyakarta dan Jawa Tengah, terdiri dari:

a. Perusahaan pemasok : Cirebon, Demak, Semarang, Kendal dan Karanganyar;

b. Kota tujuan : Sleman, Bantul, Gunung Kidul, Kulon Progo dan Yogya;

c. Armada kirim dari perusahaan (truk ekspedisi);

4. Produk yang diteliti adalah batubara.

Salah satu metode ini digunakan untuk persoalan transportasi berdimensi kecil, yaitu metode biaya terkecil (least cost method). Alokasi pertama dibuat terhadap sel yang berkaitan dengan biaya pengangkutan terendah. Sel dengan biaya terendah ini diisi sebanyak mungkin dengan mengingat persyaratan kapasitas produksi (origin) maupun permintaan tempat tujuan. Kemudian beralih ke sel termurah berikutnya dan mengadakan alokasi dengan memperhatikan kapasitas yang tersisa dari permintaan baris dan kolom. Dalam perhitungannya, metode ini membuat matriks sesuai dengan persyaratan. Dasar pemikiran metode biaya terkecil (least cost) adalah mengalokasikan sebanyak mungkin ke sel dengan biaya minimum (Fakhruddin, 2013).

\section{HASIL DAN PEMBAHASAN}

\section{IKM Potensial Pengguna Gasmin Batubara}

Berdasarkan hasil survei terhadap 414 IKM tersebut, ternyata 97 IKM merupakan pasar potensial gasmin. Lima belas perusahaan di antaranya dari kelompok makanan/minuman, 46 perusahaan dari usaha batik dan 36 dari perusahaan pengecoran alumunium (Tabel 1). Potensi pasar dari kelompok makanan/ minuman dan batik sebanyak 27 perusahaan tersebar berada di Sleman, 18 perusahaan di Bantul, 5 perusahaan di Kulon Progo, 11 perusahaan di Gunung Kidul dan 36 perusahaan di Yogya.

Dalam menghitung pemakaian batubara pada setiap pengoperasian gasmin, penulis berpedoman pada Sofaeti $d k k .$, (2016) yang menjelaskan bahwa sistem pembakaran gasmin batubara adalah kecepatan reaktivitas batubara tergaskan di dalam gasifier dengan volume tertentu, sedangkan yang dimaksud dengan gasmin kapasitas $30 \mathrm{~kg} / \mathrm{jam}$ adalah tergaskannya batubara sebanyak $30 \mathrm{~kg}$ dalam setiap 1 jam dalam reaktor gasmin. Jadi kalau gasmin tersebut bekerja enam jam dalam sehari, gasmin tersebut akan menghabiskan batubara sebanyak 180 kg. Besarnya kapasitas tersebut dijadikan dasar untuk menghitung jumlah kebutuhan batubara untuk IKM calon pengguna gasmin batubara di setiap kapasitas dan lokasi (Tabel 1) dan hasil perhitungan kebutuhan batubaranya dapat dilihat dalam Tabel 2.

\section{Pemasok Batubara}

Mengingat batubara adalah penggerak gasmin, ketersediaan batubara merupakan hal yang mutlak. Oleh karena itu, harus ada suatu lembaga/perusahaan, maupun perorangan yang mampu mengelola batubara mulai dari pengadaan dan pendistribusiannya (distributor). Model pengelolaan batubara dapat dilakukan:

1. melalui pembelian ke pemasok di tiga daerah tersebut, kemudian dikirim langsung ke masing-masing IKM pengguna gasmin sesuai dengan jumlah pemesanan;

2. dengan membangun gudang di pusat kota yaitu di Yogya, kemudian pengiriman dilakukan ke berbagai wilayah IKM yang memesan batubara; 
3. dengan membangun dan menyimpannya di suatu gudang/depo di setiap kabupaten/ kota untuk kemudian didistribusikan ke berbagai lokasi IKM pengguna gasmin sesuai jumlah pemesanan.

Ada tiga daerah yang diusulkan menjadi pemasok batubara untuk IKM pengguna gasmin batubara di DI Yogyakarta:

1. PT. GAC di Cirebon, Jawa Barat,

2. PT. MBS (Demak), PT.MSJ (Semarang), PT. BAP (Kendal) dan PT. RBI di Karanganyar, Jawa Tengah.

Batubara yang ada di pemasok didatangkan dari lokasi tambang di Kalimantan Selatan dan Kalimantan Timur melalui Pelabuhan Cirebon, Jawa Barat dan Pelabuhan Mas Semarang, Jawa Tengah. Harga masing-masing pemasok berikut biaya pengirimannya dapat dilihat dalam Tabel 3. Batubara di setiap pemasok sangat dijamin ketersediaannya. Hal ini terbukti dari volume batubara di gudang (stockpile) yang dimiliki masing-masing perusahaan pemasok batubara cukup melimpah dan selalu ada, bila suatu saat diperlukan.

\section{Model Transportasi Batubara}

Salah satu model pengelolaan batubara yang sesuai untuk pendistribusian batubara di DI Yogyakarta adalah dengan membangun atau mendirikan depo di lima kota/kabupaten. Hal ini untuk memudahkan penjualan batubara ke setiap IKM pengguna gasmin. Selanjutnya adalah bagaimana caranya memperoleh batubara beberapa lokasi yang ditawarkan ke lima kota/kabupaten dengan biaya pengiriman yang paling murah dengan mempertimbangkan biaya pengangkutan dan jarak yang tercantum dalam Tabel 3. Nilai-nilai tersebut dimasukan ke dalam model di dalam Persamaan (2), sehingga membentuk matriks seperti tercantum dalam Tabel 4 dan 5. Angka-angka tersebut digunakan untuk menghitung biaya total pengiriman minimum.

Tabel 1. Potensi pasar gasmin batubara di Daerah Istimeya Yogyakarta

\begin{tabular}{lcccccc}
\hline \multicolumn{1}{c}{ Jenis IKM } & \multicolumn{5}{c}{ Pasar potensial gasmin (unit usaha) } \\
& Sleman & Bantul & Kulon Progo & Gunung Kidul & Yogya & Jumlah \\
\hline Makanan dan Minuman & 7 & 4 & 2 & 2 & - & 15 \\
Batik & 20 & 14 & 3 & 9 & - & 46 \\
Alumunium & - & - & - & - & 36 & 36 \\
\hline Jumlah & 27 & 18 & 5 & 11 & 36 & 97 \\
\hline
\end{tabular}

Sumber :

- Disperindag (2017), diolah kembali

- Suseno dan Suherman (2020).

Tabel 2. Jumlah konsumsi batubara per bulan untuk IKM pengguna gasmin batubara di DIY (ton/bulan)

\begin{tabular}{lcccccc}
\hline \multirow{2}{*}{ Jenis IKM } & \multicolumn{5}{c}{ Konsumsi batubara (ton/bulan) } \\
\cline { 2 - 7 } & Sleman & Bantul & Kulon Progo & Gunung Kidul & Yogya & Jumlah \\
\hline Makanan dan Minuman & 34 & 17 & 8 & 8 & - & 68 \\
Batik & 88 & 63 & 15 & 42 & - & 207 \\
Alumunium & - & - & - & - & 162 & 162 \\
\hline Jumlah & 122 & 80 & 23 & 50 & 162 & 437 \\
\hline
\end{tabular}

Sumber : Hasil perhitungan tim pemasaran gasmin tekMIRA, 2017.

Tabel 3. Daftar harga dan biaya pengiriman batubara dari lokasi pemasok batubara di Cirebon (Jawa Barat), Semarang dan Karanganyar (Jawa Tengah)

\begin{tabular}{lccccc}
\hline \multicolumn{1}{c}{ Variabel } & PT.GAC & PT.MBS & PT.MSJ & PT.BAP & PT.RBI \\
& Cirebon & Demak & Semarang & Kendal & Karanganyar \\
\hline Harga (Rp./kg) & 1.300 & 1.340 & 1.250 & 1.550 & 1.375 \\
Ongkos angkut (Rp./kg) & 100 & 95 & 100 & 95 & 75 \\
Jumlah stok batubara (kg) & 56.000 & 73.000 & 43.000 & 49.000 & 90.000 \\
\hline
\end{tabular}

Sumber : Hasil survei tim pemasaran gasmin tekMIRA, 2017. 


\section{Minimisasi Biaya Transportasi dari Pemasok ke Pemesan}

Terdapat lima perusahaan batubara sebagai pemasok yaitu PT. GAC (Cirebon), PT. MBS (Demak), PT. MSI (Semarang), PT. BAP (Kendal), dan PT. RBI (Karanganyar). Terdapat lima daerah pemesan yaitu Sleman, Bantul, Gunung Kidul, Kulon Progo, dan Yogyakarta. Besarnya biaya pengiriman $(\mathrm{Rp} / \mathrm{kg})$, penawaran (kemampuan) perusahaan dan besarnya permintaan tersaji pada Tabel 4.

Jarak antara pemesan dengan pemasok juga menjadi salah satu bahan pertimbangan dalam menentukan biaya minimum pengiriman batubara (Tabel 5).
Tujuan penelitian ini adalah bagaimana perusahaan mendistribusikan produknya untuk memenuhi permintaan masing-masing daerah dengan batasan produksi masing-masing pabrik, agar biaya minimum pengiriman tercapai.

Dalam linear programming, masalah tersebut di atas dapat diformulasikan dalam model matematika yang meliputi tiga tahap di bawah ini. Pertama, variabel keputusan, menentukan variabel yang tak diketahui dan menyatakan dalam simbol matematika. Variabel keputusan dalam masalah ini adalah jumlah batubara yang dikirimkan dari masing-masing pemasok ke daerah pemesan, lihat Tabel 6 .

Tabel 4. Biaya pengiriman, kapasitas perusahaan, harga dan jenis batubara

\begin{tabular}{|c|c|c|c|c|c|c|}
\hline \multirow{2}{*}{ Pemasok } & \multicolumn{5}{|c|}{ Daerah yang dikirim (Rp./kg) } & \multirow{2}{*}{$\begin{array}{c}\text { Penawaran } \\
\text { perusahaan } \\
(\mathrm{kg})\end{array}$} \\
\hline & Sleman & Bantul & Gunung Kidul & Kulon Progo & Yogya & \\
\hline Cirebon & 100 & 100 & 100 & 100 & 100 & 98.000 \\
\hline Demak & 95 & 95 & 95 & 95 & 95 & 93.000 \\
\hline Semarang & 100 & 100 & 100 & 100 & 100 & 71.000 \\
\hline Kendal & 95 & 95 & 95 & 95 & 95 & 50.000 \\
\hline Karanganyar & 75 & 75 & 75 & 75 & 75 & 125.000 \\
\hline Jumlah Permintaan (kg) & 121.000 & 80.000 & 50.000 & 23.000 & 162.000 & \\
\hline
\end{tabular}

Tabel 5. Jarak antara pemasok dengan pemesan batubara $(\mathrm{km})$

\begin{tabular}{lccccc}
\hline \multirow{2}{*}{ Pemasok } & \multicolumn{5}{c}{ Daerah yang dikirim } \\
\cline { 2 - 6 } & Sleman & Bantul & Gunung Kidul & Kulon Progo & Yogya \\
\hline Cirebon & 315 & 329 & 377 & 292 & 318 \\
Demak & 144 & 169 & 184 & 162 & 148 \\
Semarang & 119 & 135 & 152 & 162 & 123 \\
Kendal & 119 & 161 & 178 & 163 & 123 \\
Karanganyar & 88 & 119 & 87 & 138 & 90 \\
\hline
\end{tabular}

Tabel 6. Jumlah pengiriman batubara dari pemasok ke IKM pengguna batubara

\begin{tabular}{lcccccc}
\hline \multirow{2}{*}{ Pemasok } & \multicolumn{5}{c}{ Daerah yang dikirim } & \multirow{2}{*}{ Penawaran } \\
\cline { 2 - 5 } & Sleman & Bantul & Gunung Kidul & Kulon Progo & Yogya & \\
\hline Cirebon & $\mathrm{X}_{11}$ & $\mathrm{X}_{12}$ & $\mathrm{X}_{13}$ & $\mathrm{X}_{14}$ & $\mathrm{X}_{15}$ & $\mathrm{~K}_{11}$ \\
Demak & $\mathrm{X}_{21}$ & $\mathrm{X}_{22}$ & $\mathrm{X}_{23}$ & $\mathrm{X}_{24}$ & $\mathrm{X}_{25}$ & $\mathrm{~K}_{21}$ \\
Semarang & $\mathrm{X}_{31}$ & $\mathrm{X}_{32}$ & $\mathrm{X}_{33}$ & $\mathrm{X}_{34}$ & $\mathrm{X}_{35}$ & $\mathrm{~K}_{31}$ \\
Kendal & $\mathrm{X}_{41}$ & $\mathrm{X}_{42}$ & $\mathrm{X}_{43}$ & $\mathrm{X}_{44}$ & $\mathrm{X}_{45}$ & $\mathrm{~K}_{41}$ \\
Karanganyar & $\mathrm{X}_{51}$ & $\mathrm{X}_{52}$ & $\mathrm{X}_{53}$ & $\mathrm{X}_{54}$ & $\mathrm{X}_{55}$ & $\mathrm{~K}_{51}$ \\
Permintaan & $\mathrm{K}_{11}$ & $\mathrm{~K}_{12}$ & $\mathrm{~K}_{13}$ & $\mathrm{~K}_{14}$ & $\mathrm{~K}_{15}$ & \\
\hline
\end{tabular}


Simbol-simbol dalam Tabel 6 dapat dijelaskan sebagai berikut:

$\mathrm{X}_{11}=$ jumlah batubara yang dikirimkan dari Cirebon ke daerah Sleman

$\mathrm{X}_{12}=$ jumlah batubara yang dikirimkan dari Cirebon ke daerah Bantul

$\mathrm{X}_{13}=$ jumlah batubara yang dikirimkan Cirebon ke daerah Gunung Kidul

$\mathrm{X}_{14}=$ jumlah batubara yang dikirimkan Cirebon ke daerah Kulon Progo

$\mathrm{X}_{15}=$ jumlah batubara yang dikirimkan Cirebon ke daerah Yogya

$\mathrm{X}_{21}=$ jumlah batubara yang dikirimkan dari Demak ke daerah Sleman

$\mathrm{X}_{22}=$ jumlah batubara yang dikirimkan dari Demak ke daerah Bantul

$\mathrm{X}_{23}=$ jumlah batubara yang dikirimkan Demak ke daerah Gunung Kidul

$\mathrm{X}_{24}=$ jumlah batubara yang dikirimkan Demak ke daerah Kulon Progo

$\mathrm{X}_{25}=$ jumlah batubara yang dikirimkan Demak ke daerah Yogya

$\mathrm{X}_{31}=$ jumlah batubara yang dikirimkan dari Semarang ke daerah Sleman

$\mathrm{X}_{32}=$ jumlah batubara yang dikirimkan dari Semarang ke daerah Bantul

$\mathrm{X}_{33}=$ jumlah batubara yang dikirimkan Semarang ke daerah Gunung Kidul

$\mathrm{X}_{34}=$ jumlah batubara yang dikirimkan Semarang ke daerah Kulon Progo

$\mathrm{X}_{35}=$ jumlah batubara yang dikirimkan Semarang ke daerah Yogya

$\mathrm{X}_{41}=$ jumlah batubara yang dikirimkan dari Kendal ke daerah Sleman

$\mathrm{X}_{42}=$ jumlah batubara yang dikirimkan dari Kendal ke daerah Bantul

$\mathrm{X}_{43}=$ jumlah batubara yang dikirimkan Kendal ke daerah Gunung Kidul

$\mathrm{X}_{44}=$ jumlah batubara yang dikirimkan Kendal ke daerah Kulon Progo

$\mathrm{X}_{45}=$ jumlah batubara yang dikirimkan Kendal ke daerah Yogya.

$\mathrm{X}_{51}=$ jumlah batubara yang dikirimkan dari Karang Anyar ke daerah Sleman

$\mathrm{X}_{52}=$ jumlah batubara yang dikirimkan dari Karang Anyar ke daerah Bantul

$\mathrm{X}_{53}=$ jumlah batubara yang dikirimkan Karang Anyar ke daerah Gunung Kidul

$\mathrm{X}_{54}=$ jumlah batubara yang dikirimkan Karang Anyar ke daerah Kulon Progo

$\mathrm{X}_{55}=$ jumlah batubara yang dikirimkan Karang Anyar ke daerah Yogya.
Kedua, fungsi tujuan adalah total biaya transport yang dinotasikan dengan $\mathrm{Z}$ dalam Persamaan (2):

$$
\begin{aligned}
Z= & 100(X 11+X 12+X 13+X 14+X 15) \\
& +95(X 21+X 22+X 23+X 24+X 25) \\
& +100(X 31+X 32+X 33+X 34+ \\
& X 35)+95(X 31+X 32+X 33+X 34+ \\
& X 35)+75(X 51+X 52+X 53+X 54+ \\
& X 55)
\end{aligned}
$$

Ketiga, fungsi kendala dengan menggunakan Persamaan (3) dan (4):

Batasan Permintaan:

$X_{11}+X_{21}+X_{31}+X_{41}+X_{51} \geq 129.000$
$X_{12}+X_{22}+X_{32}+X_{42}+X_{52} \geq 74.000$
$X_{13}+X_{23}+X_{33}+X_{43}+X_{53} \geq 43.000$
$X_{14}+X_{24}+X_{34}+X_{44}+X_{54} \geq 29.000$
$X_{15}+X_{25}+X_{35}+X_{45}+X_{55} \geq 162.000$

Batasan pemasokan:

$\begin{array}{ll}\text { Cirebon } \quad: & \mathrm{X}_{11}+\mathrm{X}_{12}+\mathrm{X}_{13}+\mathrm{X}_{14}+\mathrm{X}_{15} \leq \\ & 98.000 \\ \text { Demak }: & \mathrm{X}_{21}+\mathrm{X}_{22}+\mathrm{X}_{23}+\mathrm{X}_{24}+\mathrm{X}_{25} \leq \\ & 93.000 \\ \text { Semarang }: & \mathrm{X}_{31}+\mathrm{X}_{32}+\mathrm{X}_{33}+\mathrm{X}_{34}+\mathrm{X}_{35} \leq \\ & 71.000 \\ \text { Kendal }: & \mathrm{X}_{41}+\mathrm{X}_{42}+\mathrm{X}_{43}+\mathrm{X}_{44}+\mathrm{X}_{45} \leq \\ & 50.000 \\ \text { Karanganyar : } & \mathrm{X}_{51}+\mathrm{X}_{52}+\mathrm{X}_{53}+5_{4}+\mathrm{X}_{55} \leq \\ & 125.000\end{array}$

Batasan jumlah batubara:

$\mathrm{K}_{\mathrm{ij}}>0, \forall_{\mathrm{i}}, \mathrm{j}=1,2,3,4,5$

Untuk menghitung banyaknya batubara yang akan dikirim dari lokasi pemasok ke masingmasing pemesan dibantu dengan aplikasi program solver excel (Zaky dan Hadi, 2013; Mahendra, Sumarsono dan Legowo, 2016). Hasilnya dapat dilihat dalam Tabel 7 dengan penjelasan sebagai berikut:

1. Permintaan batubara dari Yogya sebesar 162 ton dapat dipasok oleh PT. GAC yang ada di Ciirebon sebesar 98 ton, PT. MBS (Demak) sebesar 64 ton.

2. Permintaan dari IKM bantul sebanyak 80 ton sebaiknya dipasok dari Semarang dan Kendal, masing-masing 27 dan 53 ton.

3. Kebutuhan batubara di Gunung Kidul cukup dipenuhi oleh pemasok dari Semarang sebanyak 23 ton

4. Permintaan batubara dari Kulon Progo dipasok dari Demak dan Semarang, masingmasing sebanyak 29 ton dan 21 ton. 
Tabel 7. Jumlah batubara terkirim dari lima lokasi pemasok ke 5 lokasi pemesan

\begin{tabular}{ccccccc}
\hline \multirow{2}{*}{ Pemasok } & \multicolumn{5}{c}{ Daerah yang dikirim } & \multirow{2}{*}{ Total } \\
\cline { 2 - 5 } & Sleman & Bantul & Gunung Kidul & Kulon Progo & Yogya & \\
\hline Cirebon & & & & & 98.000 & 98.000 \\
Demak & & & & 29.000 & 64.000 & 93.000 \\
Semarang & & 27.000 & 23.000 & 21.000 & & 71.000 \\
Kendal & & 53.000 & & & & 50.000 \\
Karanganyar & 122.000 & & & & & 125.000 \\
\hline Total & 122.000 & 80.000 & 23.000 & 50.000 & 162.000 & \\
\hline
\end{tabular}

Sumber : Hasil hitungan.

Kemudian angka-angka di dalam Tabel 7 tersebut dimasukan ke dalam Persamaan (5). Hasilnya adalah :

$$
\begin{aligned}
Z= & 100(0+0+0+0+98.000)+95(0 \\
& +0+0+29.000+64.000)+100(0 \\
& +27.000+23.000+21.000+0)+ \\
& 95(0+53.000+0+0+0)+ \\
& 75(122.000+0+0+0+0)= \\
& 39.920 .000 .
\end{aligned}
$$

Hasil perhitungan di atas dapat dinyatakan sebagai total biaya pengiriman batubara yang harus dikeluarkan dalam satu bulan dari lima lokasi pemasok ke lima lokasi pemesan yaitu sebesar Rp. 39.920.000.

\section{Depo dan Pengiriman}

Untuk memperlancar pendistribusian batubara ke masing-masing IKM pengguna gasmin, setiap daerah di DIY paling tidak harus ada satu tempat atau depo untuk menyimpan batubara. Lokasinya harus berada di tempat yang strategis, paling tidak berada di ibukota masing-masing kabupaten/kota agar setiap IKM sebagai konsumen batubara yang membutuhkan mudah untuk mendapatkannya. Depo batubara adalah tempat yang dijadikan untuk menyimpan batubara untuk dijual kembali oleh distributor/penyalur ke IKM pengguna gasmin, pemilik depo berperan sebagai ritel. Menurut Rini dan Iljanto (2014), depo atau tempat penyimpanan juga dapat diartikan kegiatan dan usaha untuk melakukan pengurusan penyelenggaraaan dan pengaturan barangbarang persediaan di dalam ruang penyimpanan. Adapun kegiatan dari penyimpanan, antara lain:

1. Menerima, menyimpan, mengatur dan menjaga keutuhan barang dalam gudang/ ruang penyimpanan agar dapat dipergunakan sesuai dengan rencana secara tertib, rapi dan aman;
2. Menyelenggarakan administrasi penyimpanan/pergudangan atas semua barang yg ada dalam gudang;

3. Melakukan stock opname secara berkala ataupun insidentil terhadap barang persediaan yang ada di dalam gudang agar persediaan selalu dapat memenuhi kebutuhan;

4. Membuat laporan secara berkala atas persediaan barang yang ada di gudang.

Apabila pengiriman batubara menggunakan truk jenis tronton dengan kapasitas 30 ton, pengiriman batubara dari Cirebon ke Kota Yogya dapat dilakukan sebanyak 6-7 kali dalam sebulan, dari Kendal dan Karanganyar ke Kulon Progo masing-masing sebanyak 2 kali dan sekali, sedangkan pengiriman dari Karanganyar ke Sleman, Bantul dan Gunung Kidul dilakukan cukup sekali dalam satu bulan. Pendirian depo batubara dapat dilakukan oleh perseorangan atau bersama-sama/Koperasi yang disebut sebagai pembeli dan penjual (trader). Sebagaimana diketahui bahwa salah satu karakter sistem pembakaran gasmin batubara adalah di samping harus menggunakan batubara $\geq 5600 \mathrm{kkal} / \mathrm{kg}$ juga harus berbentuk butiran yang berukuran 3-5 cm (Sofaeti $d k k ., 2016$ ). Untuk batubara dengan nilai kalor $\geq 5600$ $\mathrm{kkal} / \mathrm{kg}$, seluruh perusahaan pemasok batubara memilikinya, akan tetapi, untuk ukuran butir yang diperlukan ternyata hampir semua perusahaan pemasok batubara hanya menyediakan atau menjual batubara yang berbentuk asalan atau prongkolan. Kalaupun ada yang menjual, hanya satu perusahan saja yaitu PT. GAC (Cirebon) dan harganya lebih mahal karena termasuk pesanan khusus (customize). Untuk ukuran tersebut dan sudah dalam kemasan karung berukuran $25 \mathrm{~kg}$ harganya mencapai Rp. 42.500 atau Rp. 1.700 per kg sudah sampai di tempat tujuan (depo/penyalur). Apabila penyalur mengambil keuntungan 
sebesar Rp. 200 saja dari harga pokok pembelian dari pemasok, harga yang dijual oleh setiap penyalur ke IKM pengguna gasmin batubara menjadi Rp. 1.900 per kg. Depo yang dijadikan untuk tempat penyimpanan sekaligus untuk penjualan batubara (gudang dan kantor) diperlukan lahan yang cukup luas (Tabel 8).

\section{Nilai Efisiensi Penggunaan Gasmin Batubara}

Yang menjadi pertanyaan adalah apakah harga sebesar itu bagi IKM pengguna gasmin batubara masih dinilai efisien? Sebagai contoh diambil salah satu IKM yang bergerak di bidang usaha pembuatan arumanis. Berdasarkan hasil survei, setiap hari usaha ini menghabiskan gas sebanyak 4,5 tabung yang berisi $12 \mathrm{~kg}$, harga per tabung Rp. 145.000 sehingga dalam sehari menghabiskan biaya bahan bakar sebanyak Rp. 652.500. Jika disetarakan dengan penggunaan batubara akan menghabiskan sebanyak $282 \mathrm{~kg}$, dan jika harganya Rp. 1.900 per kg akan menghabiskan biaya Rp. 535.800. Nilai efisiensi yang diperoleh dari penggunaan gasmin batubara sebesar Rp. 116.700 atau $17,89 \%$, lebih hemat dibandingkan menggunakan gas LPG. Apabila jumlah jam kerja 25 hari dalam sebulan, besarnya penghematan bahan bakar akan mencapai Rp. 2.917.500.

Jika gasmin batubara harganya Rp. 70 juta, tanpa uang muka, sedangkan bunga yang harus dibayar dihitung dengan cara Bank Indonesia (2017) dan Taufiqurrochman (2013):

Bunga yang harus dibayar $=$ Pokok $x \frac{\text { Bunga } x \text { Tenor }}{100}$
Jika diketahui, bunga kredit $=11 \%$ per tahun dan lamanya cicilan atau tenor kredit $=36$ bulan (3 tahun), $\begin{aligned} \text { Bunga yang harus dibayar } & =70.000 .000 \times \frac{11 \times 3}{100} \\ & =23.100 .000\end{aligned}$

Angsuran $=\frac{\text { Plafon kredit }+ \text { Bunga yang harus dibayar }}{\text { Tenor }}$

Angsuran $=\frac{70.000 .000+23.100 .000}{36}=2.586 .111$

Berdasarkan hasil perhitungan di atas, ternyata perusahaan pembuatan arumanis ini tidak bisa mencicil sebesar Rp. 2.586.111 per bulan selama dua tahun yang disisihkan dari nilai efisiensi penggunaan gasmin batubara yang besarnya Rp. 2.917.500 per bulan.

\section{Peluang Usaha Menjadi Penyalur Batubara}

Dalam Tabel 1, dari sebanyak 97 IKM potensi pasar pengguna gasmin dengan kebutuhan batubara sebanyak $437.000 \mathrm{~kg}$, penyalur batubara akan meraup keuntungan kotor sebanyak Rp. 87.400.000 dalam sebulan. Mengingat batubara sebagai bahan bakar utama gasmin dalam mendukung kelangsungan produksi, ketersediaannya harus terjamin dan ada setiap saat diperlukan, memiliki kualitas yang baik, kontinuitas, harga terjangkau dan mudah diperoleh.

Pendapatan kotor tersebut belum mempertimbangkan hal-hal yang yang berkaitan dengan usaha menjadi penyalur batubara dan salah satu yang terpenting untuk diperhatikan adalah perhitungan investasi yang meliputi cash flow (Supriyanto, 2012), analisis break event dan tingkat pengembalian modal. Hal-hal yang dilakukan dalam analisis keuangan (Akbar, Sugiyarto dan Srihandayani, 2014) dalam pengambilan keputusan investasi, yaitu:

Tabel 8. L Luas lahan yang diperlukan untuk gudang (depo) batubara

\begin{tabular}{lccc}
\hline \multicolumn{1}{c}{ Lokasi/DEPO } & \multicolumn{2}{c}{ Penyediaan batubara $(\mathrm{kg})$} & Luas $\left(\mathrm{m}^{2}\right)$ \\
\hline Sleman & $(\mathrm{kg} / \mathrm{kg} / \mathrm{b} / \mathrm{tah})$ & 468.000 & 200 \\
Bantul & 39.000 & 504.000 & 200 \\
Gunung Kidul & 42.000 & 324.000 & 200 \\
Kulon Progo & 27.000 & 882.000 & 200 \\
Yogya & 73.500 & 2.394 .000 & 543 \\
\hline Jumlah & 199.500 & $\mathbf{4 . 5 7 2 . 0 0 0}$ & \\
\hline
\end{tabular}


1. Melakukan analisis kepekaan (sensitivity analysis);

2. Menghitung biaya investasi dan modal kerja;

3. Menghitung biaya operasi;

4. Menghitung proyeksi pendapatan;

5. Membuat modal aliran dana (cash flow modal);

6. Menentukan kriteria keekonomian suatu proyek:

a. Nilai sekarang bersih (net present value = NPV);

b. Laju pengembalian internal (internal rate of return/IRR);

c. Periode pengembalian (payback period);

7. Menerima atau menolak usulan investasi.

Variabel ekonomi yang menjadi bagian dari perhitungan tersebut antara lain:

1. Persiapan modal, modal yang digunakan dapat berasal dari uang sendiri, pinjaman atau dari investor;

2. Tempat untuk berusaha, berupa gudang tempat penyimpanan batubara termasuk di dalamnya kantor, bisa mengontrak atau membeli;

3. Tenaga kerja, menetapkan jumlah tenaga kerja, keahlian, dan besarnya gaji atau upah masing-masing pekerja. Menurut Werther (1996) dalam Riantini dkk., (2010), kecermatan dalam memilih atau merekrut tenaga kerja sangat menentukan kelangsungan kegiatan usaha;

4. Peralatan pendukung transportasi, ketersediaan kendaraan roda dua atau roda empat dibutuhkan untuk pengiriman batubara;

5. Peralatan skop, cangkul dan lain lain;

6. Persiapan perizinan, listrik, air dan lainlain.

Tabel 9 adalah perkiraan biaya investasi yang harus dikeluarkan untuk menjadi penyalur batubara di DIY.

Hasil perhitungan keekonomian (Tabel 10) menunjukkan bahwa usaha penjualan batubara dengan membangun depo di lima wilayah tersebut layak untuk diusahakan karena memiliki nilai IRR sebesar $25 \%$.

Tabel 9. Perkiraan biaya investasi usaha penyalur batubara

\begin{tabular}{|c|c|c|c|c|c|}
\hline Kebutuhan batubara (kg/tahun) & 437.000 & & 12 & & 5.244 .000 \\
\hline harga beli $=$ Rp/kg & 5.244 .000 & & 1.700 & & 8.914 .800 .000 \\
\hline harga jual $=\mathrm{Rp} / \mathrm{kg}$ & 5.244 .000 & & 1.900 & & 9.963 .600 .000 \\
\hline Profit & & & 200 & & 1.048 .800 .000 \\
\hline Komponen biaya : & & & & \multicolumn{2}{|c|}{$\begin{array}{ll} & 1.048 .800 .000\end{array}$} \\
\hline A. Biaya Produksi & & & & Rp. & 63.600 .000 \\
\hline Biaya TK ( 3 orang) (Rp/bulan/orang) & 3 orang & $@$ Rp. & 1.600 .000 & Rp. & 57.600 .000 \\
\hline Biaya listrik (Rp.) & 12 bulan & $@ R p$. & 500.000 & Rp. & 6.000 .000 \\
\hline B. Biaya Investasi & & & & Rp. & 108.000 .000 \\
\hline Biaya perizinan dan lain-lain & 1 paket & Rp. & 2.000 .000 & Rp. & 2.000 .000 \\
\hline Pembelian motor & 1 unit & Rp. & 16.000 .000 & Rp. & 16.000 .000 \\
\hline Biaya sewa gudang (Rp./tahun) & & & & Rp. & 30.000 .000 \\
\hline Pembelian mobil box bekas & 1 unit & Rp. & 50.000 .000 & Rp. & 50.000 .000 \\
\hline Biaya peralatan lainnya & 1 paket & Rp. & 10.000 .000 & Rp. & 10.000 .000 \\
\hline \multicolumn{6}{|l|}{ Asumsi : } \\
\hline \multicolumn{6}{|l|}{ Umur Proyek 10 tahun } \\
\hline \multicolumn{6}{|l|}{ Modal sendiri $30 \%$ dan Pinjaman $70 \%$} \\
\hline \multicolumn{6}{|l|}{ Bunga Pinjaman $10 \%$} \\
\hline \multicolumn{6}{|l|}{ Modal kerja 1 bulan } \\
\hline \multicolumn{6}{|l|}{ Umur Peralatan 5 tahun } \\
\hline \multicolumn{6}{|l|}{ Penyusutan garis lurus } \\
\hline \multicolumn{6}{|l|}{ Nilai Sisa $20 \%$} \\
\hline \multicolumn{6}{|l|}{ Discount Factor $8 \%$} \\
\hline Terdapat Depo di masing-masing daer & ilayah) & & & & \\
\hline
\end{tabular}


Tabel 10. Perhitungan keekonomian usaha penjualan batubara

\begin{tabular}{|c|c|c|}
\hline Total Biaya Produksi (Rp.) & $=$ & Harga beli BB + Komponen Biaya produksi (x5 lokasi) \\
\hline Total Biaya Produksi (Rp.) & $=$ & 8.090 .400 .000 \\
\hline Hasil Penjualan (Rp.) & $=$ & 96.660 .000 \\
\hline Profit (Rp.) & $=$ & 596.400 .000 \\
\hline Asumsi modal kerja untuk 1 bulan & $=$ & Total Biaya Produksi/12 = 674.200.000 \\
\hline Modal Usaha & $=$ & Modal kerja + biaya investasi $\times 5=1.214 .200 .000$ \\
\hline NPV & $=$ & $1.440 .426 .351,37$ \\
\hline IRR & $=$ & $25 \%$ \\
\hline Pengembalian modal & $=$ & 4 tahun 4 bulan \\
\hline
\end{tabular}

\section{Izin Usaha Pembelian dan Penjualan Batubara}

Mengingat perusahaan yang didirikan ini hendak melakukan pembelian atas batubara dari pihak lain dan menjualnya ke pengguna akhir (end user); sesuai ketentuan dalam Pasal 105 ayat (1) Undang-Undang No. 4 Tahun 2009 tentang Mineral dan Batubara (“UU 04/09") jo. Pasal 39 Peraturan Pemerintah No. 23 Tahun 2010 tentang Pelaksanaan Kegiatan Usaha Pertambangan Mineral dan Batubara ("PP 23/10"), tiap pihak selain pemegang IUP OP atau izin sementara yang melakukan kegiatan jual beli mineral dan/atau batubara wajib memiliki IUPK OP Pengangkutan dan Penjualan (Rizkarina, 2014). Di bawah ini adalah kutipan pasal-pasal yang dimaksud di atas:

\section{Pasal 105 ayat (1) UU 04/09.}

Tiap badan usaha yang tidak bergerak pada usaha pertambangan yang bermaksud menjual mineral dan/atau batubara yang tergali wajib terlebih dahulu memiliki IUP OP khusus pengangkutan dan penjualan;

Pasal 39 PP 23/10.

Badan usaha yang melakukan kegiatan jual beli mineral logam atau batubara di Indonesia, harus memiliki IUP Operasi Produksi khusus untuk pengangkutan dan penjualan dari menteri, gubernur, atau bupati/walikota sesuai dengan kewenangannya.

Berpedoman pada isi pasal-pasal diatas, usaha untuk menjadi penjual dan penyalur harus memiliki IUPK OP Pengangkutan dan Penjualan terlebih dahulu sebelum melakukan kegiatan pembelian batubara dengan tujuan untuk dijual lagi kepada IKM pengguna gasmin batubara. Pengajuannya dapat dilakukan secara perseorangan, koperasi maupun badan usaha (Kurnia, 2011).

\section{KESIMPULAN}

\section{Kesimpulan}

Dari hasil analisis dapat disimpulkan bahwa:

1. Permintaan batubara dari Yogya sebesar 162 ton dapat dipasok oleh PT. GAC yang ada di Cirebon sebesar 98 ton, PT. MBS (Demak) sebesar 64 ton.

2. Permintaan dari IKM Bantul sebanyak 80 ton, sebaiknya dipasok dari Semarang dan Kendal, masing-masing 27 ton dan 53 ton.

3. Kebutuhan batubara di Gunung Kidul cukup dipenuhi oleh pemasok dari Semarang sebanyak 23 ton

4. Sedangkan permintaan batubara dari Kulon Progo dipasok dari Demak dan Semarang, masing-masing sebanyak 29 ton dan 21 ton.

5. Permintaan dari IKM bantul sebanyak 80 ton, sebaiknya dipasok dari Semarang dan Kendal, masing-masing 27 ton dan 53 ton.

6. Kebutuhan batubara di Gunung Kidul cukup dipenuhi oleh pemasok dari Semarang sebanyak 23 ton

7. Sedangkan permintaan batubara dari Kulon Progo dipasok dari Demak dan Semarang, masing-masing sebanyak 29 ton dan 21 ton.

8. Lembaga-lembaga yang terlibat di dalam proses distribusi adalah koperasi atau badan usaha lainnya.

9. Salah satu lembaga penyaluran yang diperlukan adalah depo batubara. Pendiriannya dapat dilakukan oleh perseorangan atau bersama-sama/Koperasi yang disebut sebagai pembeli dan penjual (trader). 


\section{Saran}

1. Sampai saat ini belum ada pemasok/penjual batubara di DIY, oleh karena itu sebaiknya dibangun depo-depo batubara di lokasi yang strategis untuk menunjang kebutuhan batubara di IKM pengguna gasmin.

2. Mencari pemasok batubara yang mampu menyediakan batubara berukuran 3-5 cm, jika tidak ada sebaiknya didirikan depo khusus untu menyediakan batubara berukuran tersebut di sekitar IKM pengguna gasmin.

3. Di samping sebagai penjual gasmin, maka perusahaan ini juga harus mampu memberikan jaminan ketersediaan batubara pada saat IKM pengguna gasmin membutuhkannya.

\section{UCAPAN TERIMA KASIH}

Pada kesempatan ini penulis mengucapkan terima kasih kepada para penulis dalam daftar pustaka, media elektronik, media cetak dan para editor yang telah memberikan data, informasi, inspirasi dan bimbingan sehingga terwujudnya makalah ini. Penulis berharap semoga makalah ini dapat memberikan manfaat khususnya bagi penulis, para peneliti dan pemerhati gasmin.

\section{DAFTAR PUSTAKA}

Akbar, R. S., Sugiyarto dan Srihandayani, F. (2014) "Analisis dan studi kelayakan pembangunan kembali Pasar Turisari Kota Surakarta," e-Jurnal MATRIKS TEKNIK SIPIL, 2(3), hal. 242-248.

Bank Indonesia (2017) Perhitungan bunga kredit dengan angsuran, www.bi.go.id. Tersedia pada: http://www.bi.go.id/id/perbankan (Diakses: 20 Oktober 2017).

Bronson, R. (1991) Teori dan soal-soal operations research. Jakarta: Erlangga.

Fahmi, K., Tety, E. dan Rifai, A. (2014) "Analisis minimisasi biaya distribusi beras dengan menggunakan linear programming oleh Perum Bulog Divisi Riau dan KEPRI," Jom Faperta, 1(2), hal. 1-14.

Fakhruddin (2013) Analisis penerapan model transportasi distribusi dengan menggunakan metode least cost dan stepping stone pada PT.
Semen Tonasa Pangkep. Universitas Hasanuddin.

Josua, P. L. (2014) Penyelesaian simulasi angkutan tambang dengan linnier programming (Win Qsb). Universitas Trisakti.

Karo, N. B. (2016) "Analisis optimasi distribusi beras Bulog di Provinsi Jawa Barat," MIX: Jurnal Ilmiah Manajemen, VI(1), hal. 103-120.

Kurnia, J. (2011) Izin usaha pertambangan, www.hukumpertambangan.com. Tersedia pada:

https://www.hukumpertambangan.com/izinusaha/izin-usaha-pertambangan/ (Diakses: 20 Oktober 2017).

Mahendra, H. G., Sumarsono, A. dan Legowo, S. J. (2016) "Analisis tarif angkutan umum berdasarkan BOK akibat fluktuasi harga BBM dengan menggunakan program VBA Ms. Excel," e-Jurnal MATRIKS TEKNIK SIPIL, 4(1), hal. 238-245.

Nasendi, B. D. dan Affendi, A. (1985) Program linear dan variasinya. Jakarta: Gramedia.

Nirwansah, H. dan Widowati (2007) "Efisiensi biaya distribusi dengan metode transportasi," in Parhusip, H. A. et al. (ed.) Prosiding Seminar Nasional Applikasi Sains dan Matematika dalam Industri. Salatiga: Tisara Grafika dan Fakultas Sains \& Matematika Universitas Kristen Satya Wacana, hal. 133-139.

Riantini, L. S., Trigunarsyah, B., Abidin, I. dan Latief, Y. (2010) "Penentuan peringkat faktor risiko dalam rekrutmen tenaga kerja yang mempengaruhi biaya tenaga kerja pada proyek," Jurnal Teknik Sipil, 12(3), hal. 177184. doi: 10.5614/jts.2005.12.3.5.

Rini, R. A. dan Iljanto, S. (2014) Studi kasus analisis sistem penyimpanan obat di Sub Bagian Logistik Rumah Sakit Graha Permata Ibu tahun 2014. Universitas Indonesia.

Rizkarina, W. (2014) Perizinan jual beli batubara, www.hukumonline.com. Tersedia pada: https://www.hukumonline.com/klinik/detail/u lasan/lt528d6ff8084f7/perizinan-jual-belibatubara/ (Diakses: 20 Oktober 2017).

Simbolon, L. D., Situmorang, M. dan Napitupulu, N. (2014) "Aplikasi metode transportasi dalam optimasi biaya distribusi beras miskin (Raskin) pada Perum Bulog Sub Divre Medan," Saintia Matematika, 2(3), hal. 299-311.

Sofaeti, Y., Effendi, M. A. A., Yusnanto dan Saputra, R. (2016) Tantangan dan peluang teknologi 
gasifikasi skala industri kecil (Gasmin) untuk menggantikan BBM dan kayu bakar menuju komersialisasi. Bandung: Puslitbang tekMIRA.

Supranto, J. (1983) Linear programming. Jakarta: Fakultas Ekonomi Universitas Indonesia.

Supriyanto (2012) "Business plan sebagai langkah awal memulai usaha," Jurnal Ekonomi dan Pendidikan, 6(1), hal. 73-83. doi: 10.21831/jep.v6i1.590.

Suseno, T. dan Suherman, I. (2020) "Analisis pengukuran pasar gasmin batubara di Daerah Istimewa Yogyakarta," Jurnal Teknologi Mineral dan Batubara, 16(1), hal. 47-56. doi: 10.30556/jtmb.Vol16.No1.2020.1042.

Taufiqurrochman, C. (2013) "Seluk beluk tentang konsep bunga kredit bank," Jurnal Kebangsaan, 2(3), hal. 12-16.
Wijayanti, D. K. (2011) Aplikasi metode transportasi dengan program solver dalam meminimumkan biaya pengiriman produk (Studi kasus PT. Rajaa Tunggal). Universitas Negeri Semarang.

Zaky, G. A. dan Hadi, F. (2013) "Model konseptual perencanaan transportasi bahan bakar minyak (BBM) untuk wilayah kepulauan (Studi kasus: Kepulauan Kabupaten Sumenep)," Jurnal Teknik POMITS, 2(1), hal. 1-5.

Zulfaqor (2017) Studi kasus target produksi tambang terbuka batubara untuk kapasitas pasar (PLTU) menggunakan pola distribusi/angkutan tambang yang optimal. UIN Syarif Hidayatullah. 
